\title{
Bilateral pectoralis advancement flaps and transverse plate fixation system for sternal reconstruction in the complicated sternal wound
}

\author{
JM De Raet ${ }^{1 *}$, H De Praetere $^{2}$, PT Sergeant ${ }^{2}$ \\ From 23rd World Congress of the World Society of Cardio-Thoracic Surgeons \\ Split, Croatia. 12-15 September 2013
}

\section{Background}

Complicated sternal wound infection after cardiac surgery has an incidence of $0.4-6.9 \%$ and mortality of $7-80 \%$. Aim was to report our experience with bilateral pectoralis advancement flaps and a transverse plate fixation system for sternal reconstruction in the complicated sternal wound.

\section{Methods}

Between 2008 and 2012, 24 patients with a complicated sternal wound underwent a sternal reconstruction with bilateral pectoralis advancement flaps and a transverse plate fixation system. The median age of the cohort (4 female and 20 males), was 65.8 years (range: 33-83 years). In 19 patients, a bilateral internal thoracic artery had been used. Considerable preoperative risk factors were present: morbid obesity with Body Mass Index (BMI) $\geq 35$ (range: 35 - 49.7: 13 patients); chronic obstructive pulmonary disease (COPD) without steroid therapy preoperatively (7 patients); diabetes mellitus (7 patients). Concomitant laparoscopically harvested omentoplasty was performed in case of overt mediastinits (4 patients). In 14 cases, the mediastinal wound was prepared with negative pressure wound therapy following surgical debridement. An internal fixation of the sternum by titanium locking plates with sternal and rib-to-rib fixation and bilateral pectoralis advancement flaps were performed in all patients. The postoperative course of was followed by clinical follow-up.

\section{Results}

Early postoperative sternal stability was seen in all 24 patients. The 30 -day perioperative mortality rate was zero, with an overall survival of $100 \%$ until today. Postoperatively $2(8.3 \%)$ small superficial and 1 (4.1\%) deep surgical site infection (SSI) were appreciated. Follow-up ranged from 6.5 to 54.5 months (median: 26.5 months).

\section{Conclusions}

Combination of bilateral pectoralis advancement flaps and a transverse plate fixation system for sternal reconstruction can contribute to a successful outcome following a complicated sternal wound.

\section{Authors' details}

'Department of Cardiac Surgery, Heart Center Leipzig, University of Leipzig, Leipzig, Germany. ${ }^{2}$ Department of Cardiac Surgery, University Hospitals Leuven, Leuven, Belgium.

Published: 11 September 2013

doi:10.1186/1749-8090-8-S1-P57

Cite this article as: De Raet et al:: Bilateral pectoralis advancement flaps and transverse plate fixation system for sternal reconstruction in the complicated sternal wound. Journal of Cardiothoracic Surgery 20138 (Suppl 1):P57.

\footnotetext{
* Correspondence: janderaet@hotmail.com

'Department of Cardiac Surgery, Heart Center Leipzig, University of Leipzig, Leipzig, Germany

Full list of author information is available at the end of the article
}

(c) 2013 De Raet et al; licensee BioMed Central Ltd. This is an Open Access article distributed under the terms of the Creative Commons 